Sharif University of Technology
Scientia Iranica
Transactions A: Civil Engineering
IRAENTIA
http://scientiairanica.sharif.edu

\title{
Effect of structural uncertainties on seismic performance of moment frame rehabilitated with steel shear wall
}

\author{
M. Maddahi ${ }^{a}$, M. Gerami ${ }^{a, *}$, and H. Naderpour ${ }^{b}$ \\ a. Department of Earthquake Engineering, Semnan University, Semnan, Iran. \\ b. Department of Structural Engineering, Semnan University, Semnan, Iran.
}

Received 30 August 2019; received in revised form 10 June 2020; accepted 7 December 2020

\author{
KEYWORDS \\ Rehabilitation; \\ Uncertainty; \\ Reliability; \\ Incremental dynamic \\ analysis; \\ Steel shear wall.
}

\begin{abstract}
In performance-based engineering, conservatism in acceptance criteria at structural performance levels has increased the cost of retrofitting. In seismic rehabilitation of structures, uncertainties associated with existing structures have been studied and rehabilitation guidelines have been applied to deal with these uncertainties in terms of reliability index. The secondary system, which is added to the existing structure, is subject to uncertainties in seismic rehabilitation of structures. These uncertainties can escalate the uncertainties of rehabilitated structures and may change the analysis results such as reliability index parameter, values of fragility, and inter-story drift. Therefore, this study investigated the reliability of the structure rehabilitated with steel shear wall and performed a parametric study on the reliability index. The selected structure was a steel moment frame, which was rehabilitated by the steel shear wall. The structure was subject to incremental dynamic analysis before and after rehabilitation with probabilistic variables. Based on the results, the values of the reliability index were obtained for the rehabilitated structure in the presence of uncertainties. According to results, structural rehabilitation reduced failure probability and consideration of uncertainties in the rehabilitated structure increased the probability of failure. Therefore, existing conservatism was reduced.
\end{abstract}

(C) 2021 Sharif University of Technology. All rights reserved.

\section{Introduction}

Conservatism in acceptance criteria at structural performance levels is an important problem and causes high costs for retrofitting and reconstruction. It is no wonder that, sometimes, the results of performance evaluations are inaccurate. Siahos and Dritsos [1] evaluated the seismic performance of Reinforced Concrete

\footnotetext{
*. Corresponding author. Tel.: +98 2331535208;

Fax: +98 2331535212

E-mail addresses: m.maddah93@semnan.ac.ir ( $M$.

Maddahi); mgerami@semnan.ac.ir (M. Gerami);

naderpour@semnan.ac.ir (H. Naderpour)
}

(RC) structures according to conventional regulations through pushover analysis. They found that all methods had overestimated the observed damage. Acun and Sucuoglu [2,3] tested 12 full-scale columns designed for bending failure. They proved that the performance limits applied to common columns by the regulation were very conservative in terms of test results, which might lead to misleading outcomes when assessing the seismic hazard of structures. Also, Ricci et al. [4] tested old reinforced concrete columns and observed significant conservatism concerning the results of the plastic deformation model. Therefore, studies on design criteria of regulations have shown that uncertainties in the estimation of structural engineering problems are in evitable. 
Structural system properties such as material parameters, external loads, incomplete models, and human factors are uncertain. Structural loads and member resistance cannot be definitively modeled with uncertainties when the structural response is simulated. Although it is impossible to achieve absolute safety, the possible range of demands and resistance can be predicted and idealized. Consequently, probabilistic design philosophy can provide a safety level for structures by predicting the probability of failure.

Hacking [5] categorized uncertainty sources in probabilistic methods that are either aleatory or epistemic. Aleatory uncertainty is irreducible and results from random changes in phenomena. Thus, these uncertainties cannot be reduced. Structural parameters such as material properties, geometry, and loads are regarded as aleatory uncertainties. In contrast, epistemic uncertainty can be reduced and it occurs due to insufficient data. This uncertainty diminishes with increasing data. In 2007, considering different uncertainties, Zareian and Krawinkler proposed a probabilistic method [6]. Dolsek [7] studied the effects of epistemic uncertainty on the seismic capacity of a 4-story concrete moment frame and selected a set of structural modeling parameters as probabilistic variables.

Vamvatsikos and Fragiadakis [8] used the moment-rotation relationship with multi-linear nondeterministic backbone curves for plastic beams. Using different statistical tools, they studied the effect of these uncertainties on the performance of a 9-story steel moment frame. This study considered the backbone curve with six unknown parameters including yield moment, ratio of post-yield hardening, end moment, descending branch slope, remaining moment, and ultimate rotation.

In 2014, Vamvatsikos [9] studied the uncertainties of the model parameters. He investigated the effects of these uncertainties on the seismic performance of structures by means of a new algorithm and the Latin Hypercube Sampling (LHS). In the same year, Kaveh et al. [10] considered elastic modulus, loads, and geometric parameters as probabilistic variables. They tried to reduce the reliability index by presenting an algorithm. Mathiasson and Medina [11] studied the collapse probability of steel moment frame structures with consideration of aleatory and epistemic uncertainties.

Torabian and Taghikhany [12] used the singledegree-of-freedom system to investigate the uncertainties of steel moment frames. Using Incremental Dynamic Analysis (IDA) and the LHS method, they investigated the aleatory and epistemic uncertainties of structures. Kazantzi et al. [13] evaluated the effects of uncertainty in resistance and ductility on the seismic performance of a 4-story steel moment frame. They used the force-deformation relationship for the model derived from Lignos and Krawinkler's works [14]. They showed that ignoring the uncertainties of a model might yield non-conservative estimates of fragility in case of local damage. In 2015, considering the reliability of a structural system equipped with a damper, Tubaldi et al. investigated the uncertainties of seismic records [15].

In 2016, Asgarian and Ordoubadi [16] evaluated other modeling parameters. They considered four probabilistic variables including equivalent viscous damping, effective seismic mass, yield strength, and ultimate strength of steel. In the same year, Hajirasouliha et al. [17] studied the effect of uncertainty in structural properties and ground motion on the performance of braced frames. They examined a set of 5-, 10-, and 15-story structures in various seismic simulations and inspected the effects of mechanical properties of structural elements, damping ratio, and seismic stimulation using the Monte Carlo simulation method. In 2016, Zhang et al. [18] studied uncertainties in steel structures and considered uncertainties in crosssection and structural loads as probabilistic variables. In the same year, Holicky et al. [19] attempted to improve the definitions of model uncertainty. Using the model and empirical results, they proposed a general methodology to determine the model' uncertainty quality.

In 2017, Dyanati et al. [20] considered uncertainties in the demand and capacity of the braced frame system and examined the seismic performance of these structures. In 2018, Jiang and Ye [21] took into account different sources of aleatory and epistemic uncertainties for seismic risk assessment of the structures. Using the LHS method, they modeled random variables. They showed that the uncertainties had a significant impact on seismic risk assessment of the structures. In 2019, Norouzi and Gerami [22] studied the effect of uncertainty in characteristics of the ground motion on the performance of steel moment frames. Using the failure mechanism theory, Piluso et al. [23] developed the seismic design method for Moment-Resisting Frames (MRFs) with consideration of the material uncertainties.

These researches have investigated the seismic design of structures. In these researches, uncertainties in the designed structures have been considered. In seismic regulations such as FEMA-P695 [24], the model and ground motion uncertainties are separately considered. In these regulations, uncertainties are taken into consideration based on qualitative data in existing structures. In seismic rehabilitation of structures, the secondary system, added to the existing structure, is subject to uncertainties. These uncertainties may increase the uncertainties of the rehabilitated structure.

In Section 2, a 3-story steel moment frame is selected and modeled as two-dimensional. In Section 3, 


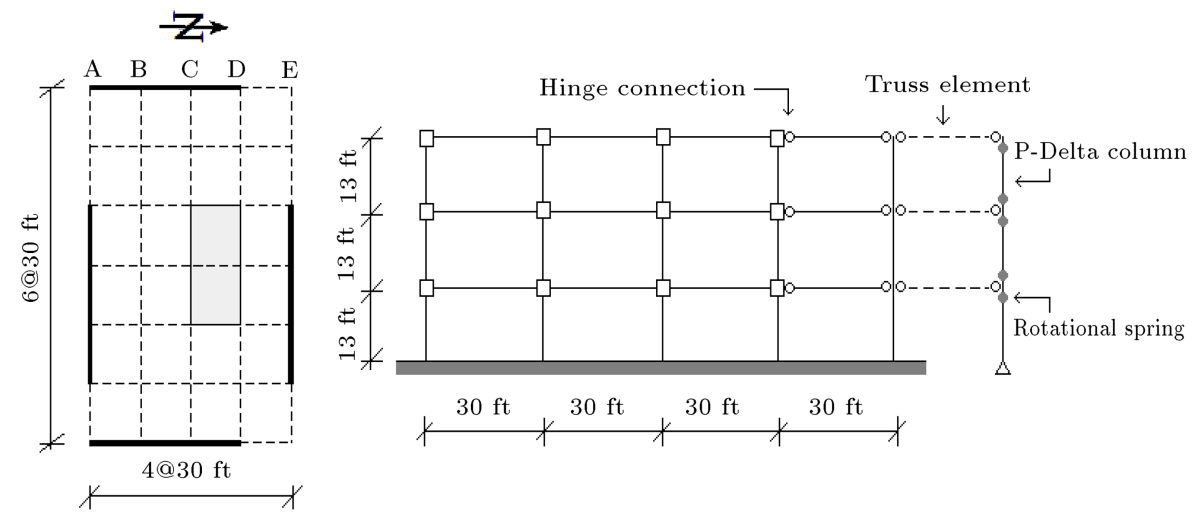

Figure 1. Plan and height of the 3-story structure [25].

the structure is analyzed and rehabilitated with a steel shear wall. Near-field and far-field records are used for IDA. In Section 4, considering the probabilistic variables, an effective number of structural models are generated. The quantification of uncertainties associated with the steel shear wall is investigated to evaluate the uncertainties in seismic rehabilitation. The seismic performance evaluation of structures should be performed using reliability-based methods. In this study, using the reliability methods, the effect of uncertainties on the seismic performance of the rehabilitated structure is studied. In Sections 5 and 6 , the results of the analysis and conclusions are presented, respectively.

\section{The structural model for seismic performance evaluation}

\subsection{Selected structural model}

In this study, a 3-story steel moment frame was selected, which was designed based on the UBC1994 regulation [25]. In this structure, all common requirements of UBC1994 code were taken into account for seismic and gravity design. The structure, located in the center of Los Angeles and on stiff soil, was designed as an office building and a steel moment frame. In this structure, perimeter steel MRFs were used as structural systems. The plan and height of the structure are given in Figure 1. The structure of the lowest floor had rigid connections and the damping of the structure was considered to be $2 \%$. The beams and columns were characterized by a yield strength of $50 \mathrm{kip}$ and a modulus of elasticity of 29,000 ksi. The sections assigned to structural members are presented in Table 1.

Regulations, published after the Northridge earthquake, have made design recommendations for the construction of plastic hinge in the beam and away from the column surface. The displacement of plastic hinge away from the column surface was done by increasing the beam capacity on the column surface by adding cover plates to the beam flange or reducing the resistance of beam away from the column surface through the reduction of the beam section.

By using the point plastic hinge on the beam and away from the column surface, the plastic behavior of beams was modeled. For point plastic hinges, a bilinear moment-rotation relationship with strain hardening of $3 \%$ was used. Also, there was a bilinear momentrotation relationship with strain hardening of $3 \%$ for the column.

OpenSees software [26] uses a combination of rigid elements and rotational spring for modeling the panel zone directly. Figure 2 presents the details of the panel zone. Rotational spring provides stiffness and

Table 1. Sections of the studied structure [25].

\begin{tabular}{|c|c|c|c|c|c|}
\hline \multirow{3}{*}{ Story } & \multicolumn{3}{|c|}{ Moment-resisting frame } & \multicolumn{2}{|c|}{ Gravity frames } \\
\hline & \multicolumn{2}{|c|}{ Columns } & \multirow{2}{*}{ Beam } & \multirow{2}{*}{ Columns } & \multirow{2}{*}{ Beam } \\
\hline & Exterior & Interior & & & \\
\hline 1 & $\mathrm{~W} 14 \times 257$ & $\mathrm{~W} 14 \times 311$ & $\mathrm{~W} 30 \times 116$ & $\mathrm{~W} 14 \times 68$ & $\mathrm{~W} 16 \times 26$ \\
\hline 2 & $\mathrm{~W} 14 \times 257$ & $\mathrm{~W} 14 \times 311$ & $\mathrm{~W} 30 \times 116$ & $\mathrm{~W} 14 \times 68$ & $\mathrm{~W} 16 \times 26$ \\
\hline 3 & $\mathrm{~W} 14 \times 257$ & $\mathrm{~W} 14 \times 311$ & $\mathrm{~W} 24 \times 62$ & $\mathrm{~W} 14 \times 68$ & $\mathrm{~W} 14 \times 22$ \\
\hline
\end{tabular}




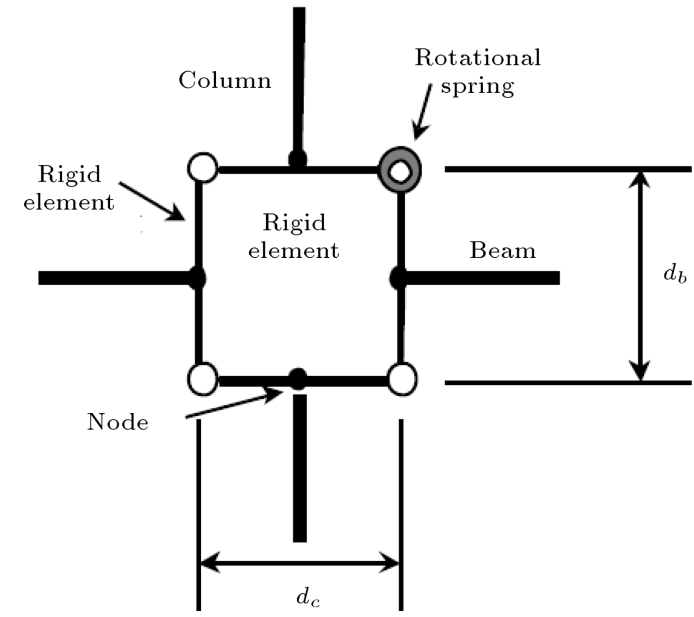

Figure 2. Analytical model for the panel zone [25].

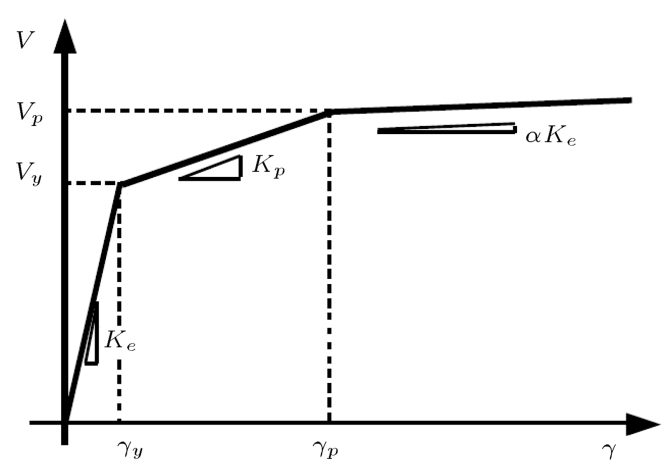

Figure 3. The trilinear shear force-shear strain relationship for the panel zone [25].

shear strength of the panel zone with a trilinear shear force-shear strain relationship. The shear force-shear strain relationship proposed by Krawinkler is shown in Figure 3, which is used to describe the shear behavior of the panel zone in this study. The control values for yield force $V_{y}$, plastic force $V_{p}$, yield strain $\gamma_{y}$, and plastic strain $\gamma_{p}$ are given by:

$$
\begin{aligned}
& V_{y}=0.55 f_{y e} d_{c} t_{w}, \\
& V_{p}=V_{y}\left(1+\frac{3 b_{c f} t_{c f}^{2}}{d_{b} d_{c} t_{w}}\right), \\
& \gamma_{y}=\frac{f_{y e}}{\sqrt{3} G}, \\
& \gamma_{p}=4 \gamma_{y},
\end{aligned}
$$

where $d_{c}$ is column depth; $b_{c f}$ is column flange width; $d_{b}$ is beam depth; $t_{w}$ is web thickness; $t_{c f}$ is column flange thickness; and $G$ is shear modulus.

The elastic stiffness, $K_{e}$, and the post-yield stiffness, $K_{p}$, are calculated as the slopes of the elastic and plastic zone, respectively.

\subsection{Gravity and lateral loading}

The studied structure is a steel structure consisting of perimeter steel MRFs and interior Gravity Frames (GFs). In this structure, the lateral load is carried by the perimeter MRFs and the gravity load is carried by perimeter MRFs and interior GFs. In Figure 1, the perimeter MRFs are represented by continuous lines and the interior GFs are represented by dashed lines. The gravity load of the entire structure is 2281 kips on the roof floor and 2108 kips on the other floors (including dead load plus $20 \%$ live load). Due to the symmetry of the structure, half of the structure is considered in modeling. In the gravity load of the structure, the contribution of parameter MRF is determined based on the proportion of the structure loading surface to the floor area. The gravity load of each floor is applied to the beams of the floor, and lateral load is applied as a point load at the height of the structure.

In two-dimensional modeling, the effect of the interior frames and orthogonal steel moment frames is not considered. A gravity equivalent column ( $p$-delta column) has been used to consider the effect of interior frames. The contribution of the $p$-delta column of a gravity load is equal to the gravity load of the floor minus the gravity load of the perimeter MRF (with consideration of the effect of the structure symmetry).

On each floor, the inertia moment of the $p$-delta column is equal to the inertia moment of columns of interior frames and orthogonal steel moment frames. At the beginning and end of the $p$-delta column (except for the beginning of the column of the first floor), bending spring with low stiffness is defined to prevent the transmission of bending moment. The $p$-delta column is connected to the steel moment frame by beams with stiffness and strength equivalent to the interior frame beams.

After modeling using OpenSees software, the structure was subjected to pushover analysis. The pushover curve derived from this modeling and modeled structures in Gupta and Krawinkler's report [25] is presented in Figure 4. The lateral load for pushover analysis is considered according to UBC1994 regulation.

\section{Structure rehabilitated with steel shear wall}

In this study, the structure was modeled as twodimensional and evaluated to investigate the need for rehabilitation. For seismic evaluation, the nonlinear static analysis was used, while the bilinear momentrotation relationship was employed for modeling the nonlinear behavior of members in the nonlinear static analysis.

Based on the evaluations performed, weaknesses of the structure were determined. The use of appro- 


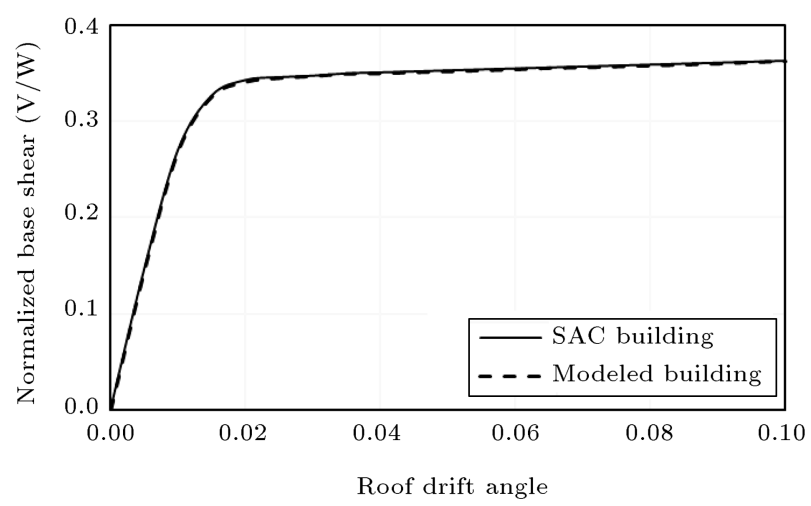

Figure 4. Pushover curve of the SAC structure and the studied structure.

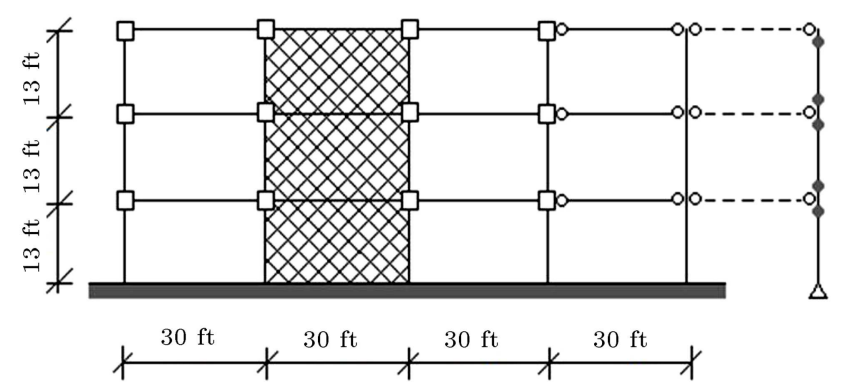

Figure 5. Structure rehabilitated with the steel shear wall.

priate methods is essential for correcting the weaknesses and performing the rehabilitation. According to requirements of the structure, a proper strategy should be applied to rehabilitation. In this paper, system rehabilitation was used and the steel shear wall was considered for the rehabilitation of the existing structure.

When the structure is under rehabilitation with a steel shear wall, the stress concentration in columns grows along the shear wall; thus, these columns are particularly needed for rehabilitation. A steel shear wall with a low yield strength $\left(F_{y}=35 \mathrm{kip}\right)$ was used to prevent or mitigate this problem. Characteristics of the employed shear wall are reported in Table 2. Figure 5 displays the structure rehabilitated with a steel shear wall. The studied structure was a steel structure consisting of perimeter MRF and the middle span of the perimeter MRF was rehabilitated with the

Table 2. Characteristics of the steel shear wall used to rehabilitate the structure.

\begin{tabular}{cccc}
\hline Story & $\begin{array}{c}\text { Thickness of } \\
\text { steel shear wall } \\
\text { (inch) }\end{array}$ & $\begin{array}{c}\boldsymbol{F}_{\boldsymbol{y}} \\
\text { (kip) }\end{array}$ & $\begin{array}{c}\boldsymbol{E} \\
(\mathbf{k s i})\end{array}$ \\
\hline 1 & 0.22 & & \\
2 & 0.22 & 35 & 29000 \\
3 & 0.12 & & \\
\hline
\end{tabular}

shear wall. The strip model was used to model the steel shear wall in OpenSees software.

\section{Estimation of probabilistic seismic performance}

\subsection{Probabilistic seismic performance evaluation method}

At this step, the structure is studied using IDA. IDA is one of the most recent design methods based on the performance in earthquake engineering, which describes the behavior of the structure at different earthquake intensities. Due to the dynamic nature of this method, the obtained results represent a more realistic behavior of the structure.

In the IDA method, a certain numerical model of the structure is considered; hence, this method includes only aleatory uncertainties (uncertainties related to various seismic records). In an extended method, with the probabilistic distribution of the structural model, IDA can be done. Thus, this method includes both aleatory and epistemic uncertainties.

The required records must be selected and scaled to conduct the IDA. In this study, ground motion data include the number of far-field and near-field records with different frequency contents, durations, and magnitudes. The near-field records are considered at a distance of $15 \mathrm{~km}$ from the fault [27]. In this study, all of the selected records are of soil D in accordance with the classification of NEHRP's site, given the structure is located on stiff soil. Also, scaling is done after selecting the records. Tables 3 and 4 outline the selected far-field and near-field records.

According to NIST GCR 11-917-15 [28], for twodimensional analyses, ground motions should be scaled such that the mean value of the response spectrum for a set of ground motions is not lower than that of the site design response spectrum within the periodic range of $0.2 \mathrm{~T}$ to $1.5 \mathrm{~T}$. Figure 6 illustrates the design spectrum

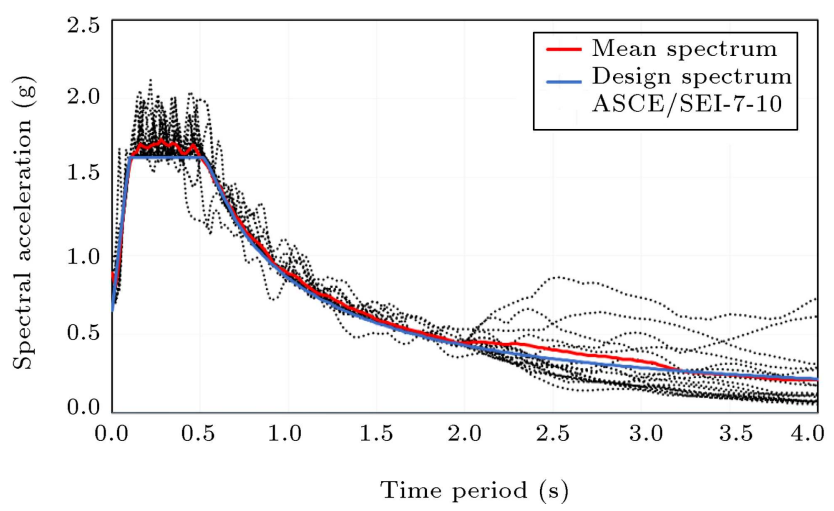

Figure 6. The design spectrum and the scaled spectrum of selected records along with the average range of these records. 
Table 3. Details of the far-field records.

\begin{tabular}{clclccc}
\hline No. & \multicolumn{1}{c}{ Earthquake } & Year & \multicolumn{1}{c}{ Station } & $\boldsymbol{M}_{\boldsymbol{W}}$ & $\boldsymbol{R}_{\boldsymbol{i b}}(\mathbf{k m})$ & $\boldsymbol{R}_{\boldsymbol{r u p}}(\mathbf{k m})$ \\
\hline 1 & San Fernando & 1971 & 2516 Via Tejon PV & 6.61 & 55.2 & 55.2 \\
2 & Tabas, Iran & 1978 & Ferdows & 7.35 & 89.76 & 91.14 \\
3 & Imperial Valley06 & 1979 & Coachella Canal \#4 & 6.53 & 49.1 & 50.1 \\
4 & Victoria, Mexico & 1980 & SAHOP Casa Flores & 6.33 & 39.1 & 39.3 \\
5 & Coalinga-01 & 1983 & Parkfield-Cholame & 6.36 & 55.05 & 55.77 \\
6 & N. Palm Springs & 1986 & Hesperia & 6.06 & 71.7 & 72.97 \\
7 & Whittier Narrows-01 & 1987 & Canyon Country-w lost & 6 & 44.88 & 48.18 \\
8 & Loma Prieta & 1989 & Richmond City Hall & 6.93 & 87.78 & 87.87 \\
9 & Landers & 1992 & Baker Fire Station & 7.28 & 87.94 & 87.94 \\
10 & Northridge-01 & 1994 & Huntington bch-Waikiki & 6.69 & 66.43 & 69.5 \\
\hline
\end{tabular}

Table 4. Details of the near-field records.

\begin{tabular}{clclccc}
\hline No. & \multicolumn{1}{c}{ Earthquake } & Year & \multicolumn{1}{c}{ Station } & $\boldsymbol{M}_{\boldsymbol{W}}$ & $\boldsymbol{R}_{\boldsymbol{i b}}(\mathbf{k m})$ & $\boldsymbol{R}_{\boldsymbol{r u p}}(\mathbf{k m})$ \\
\hline 1 & Parkfield & 1966 & Cholame-Shandon & 6.19 & 12.9 & 12.9 \\
2 & Gazli & 1976 & Karakyr & 6.80 & 3.92 & 5.46 \\
3 & Coalinga & 1983 & Pleasant Valley p.p. bldg & 6.36 & 7.69 & 8.41 \\
4 & N. Palm Springs & 1986 & North Palm Springs & 6.06 & 0 & 4.04 \\
5 & Whittier Narrows-01 & 1987 & Santa Fe Springs E. Joslin & 6 & 11.47 & 14.49 \\
6 & Superstition Hills-02 & 1987 & Parachute Test Site & 6.54 & 0.95 & 0.95 \\
7 & Loma Prieta & 1989 & Gilroy Araay \#2 & 6.93 & 10.38 & 11.07 \\
8 & Erzican, Turkey & 1992 & Erzican & 6.69 & 0 & 4.38 \\
9 & Kobe & 1995 & KJMA & 6.9 & 0.94 & 0.96 \\
10 & Chi-Chi & 1999 & TCU065 & 7.62 & 0.57 & 0.57 \\
\hline
\end{tabular}

and scaled spectrum of selected records along with the average range of these records.

\subsection{Quantification of the considered uncertainties}

Despite significant uncertainties in the seismic demand and capacity, the results of the design and evaluation of the seismic performance of structures will be valid only if these uncertainties have been considered with a realistic approach. In other words, by using reliability methods, designing and evaluating the seismic performance of structures should be done.

The purpose of reliability is to express the completeness of failure probability. Each reliability issue has two components: random variables and state functions. Random variables express uncertainty in the problem, while the state functions define the failure event. In general, the state function is defined as in Eq. (5):

$$
g(R, S)=R-S,
$$

where $g$ denotes the limit state function and the state $g<0$ represents the failure of the structure. $R$ and $S$ denote the capacity and demand, respectively, which contain a set of random variables. By using basic statistical distribution functions such as Probability Density Function (PDF), the occurrence of these variables is defined. The failure probability, $P_{f}$, is expressed as multiple integrals in Eq. (6):

$$
P_{f}=P(g \leq 0)=\int_{g \leq 0} \cdots \int f(x) d x
$$

where $f(x)$ is the PDF for basic random variables. Variations of statistical distribution for the randomized model and the number of random variables can complicate the evaluation of Eq. (6) using the integration method. On the other hand, simulation techniques and second-moment methods are suitable for solving structural reliability issues. In other words, reliability methods constitute a solution to this integral and can solve it with different approaches. First-order second-moment methods, first-order reliability, secondorder reliability, sampling method, and Monte Carlo simulation are examples of reliability methods. In this study, IDA analysis was used to calculate the uncertainties caused by random parameters of the structural system. IDA analysis, coupled with Monte 
Table 5. Statistical characteristics of random input variables.

\begin{tabular}{lccccc}
\hline \multicolumn{1}{c}{ Name } & Symbol & Mean & $\begin{array}{c}\text { Coefficient } \\
\text { of variation }\end{array}$ & Distribution & Reference \\
\hline Strain hardening ratio & $\alpha$ & 0.02 & 0.4 & Normal & Sadowski et al. [32,33] \\
Rayleigh's damping & $\zeta$ & 0.02 & 0.4 & Normal & Porter et al. [34] \\
Yield strength & $F_{y}$ & $35 \mathrm{kip}$ & 0.07 & Lognormal & Melchers [35], JCSS [36] \\
\hline
\end{tabular}

Carlo simulation and sampling, considers uncertainties of various parameters in the capacity and demand of real systems.

Initially, the structure with basic parameters underwent IDA analysis with selected seismic records. The selected records involve extensive variations in ground motion characteristics. The results of this step were associated with the uncertainty caused by various seismic records. At the next step, assuming Rayleigh's damping, yield strength, and strain hardening of the force-deformation relationship of steel shear wall as probabilistic variables, an effective number of structural models were generated. Then, each structural model was subject to IDA analysis for the selected records. The results of this step included aleatory and epistemic uncertainties.

Table 5 presents the statistical characteristics of selected probability variables. In general, with respect to probabilistic variables, 120 structural models were used for three-story structures rehabilitated with the steel shear wall. FEMA356 [29] proposed the use of maximum drift ratio to capture the structural performance levels and the corresponding damage of structural components. In this study, inter-story drift ratio $(\theta)$ was employed to measure the damage. The inter-story drift ratio was measured as the ratio of relative displacement between floors to story height.

FEMA356 proposed Immediate Occupancy (IO), Life Safety (LS), and Collapse Prevention (CP) performance levels as three structural performance levels with allowable drift ratios of $0.7 \%, 2.5 \%$, and $5 \%$, respectively. In this study, spatial acceleration in the main period of the structure $\left(S_{a}\right)$ was considered to measure seismic intensity. Fragility function $F_{r}(x)$, which indicates the exceedance probability of different damage states, is expressed by Eq. (7) [30]:

$$
F_{r}(x)=\phi\left[\left(\ln x-\ln \bar{S}_{a}\right) / \beta_{R}\right]
$$

where $\bar{S}_{a}$ is the median value of structural fragility in unit $S_{a}, \beta_{R}$ is the standard deviation of lognormal of the system fragility, and $\phi$ denotes standard normalized cumulative distribution function. Distribution parameter, $\beta_{R}$, which expresses the uncertainties associated with seismic demand and structural capacity, is calculated through Eq. (8):

$$
\beta_{R}=\sqrt{\beta_{D \mid S_{a}^{2}}+\beta_{c}^{2}}
$$

The uncertainty in seismic demand $\left(\beta_{D \mid S_{a}}\right)$ is expressed by dispersion at $\theta_{\max }$, while the uncertainty in structural capacity $\left(\beta_{c}\right)$ depends on different states of structural damage. $\beta_{c}$ is equal to 0.25 for IO and LS limit states and it is 0.15 for CP limit state [31]. The annual exceedance probability of the limit state is defined by Eq. (9) [30]:

$$
P_{L S}=k_{0} \bar{S}_{a}^{-k} \exp \left[\frac{\left(k \beta_{R}\right)^{2}}{2}\right]
$$

where $k_{0} \bar{S}_{a}^{-k}$ indicates a seismic hazard and the exponential term is the correction coefficient, which applies the variability of demand and capacity. In Eq. (9), $k_{0}$ and $k$ denote the risk scale and the slope of the seismic hazard curve, respectively.

\section{Results and discussion}

\subsection{Incremental dynamic analysis}

In the first section of results, summarized IDA curves (16th, 50th, and 84th percentiles of capacity) are given in Figures 7 and 8 for pre- and post-rehabilitation states of the structure in three limit states (IO, LS, and $\mathrm{CP}$ ). Pre-rehabilitation results are presented as the baseline state. IDA curves in Figures 7 and 8 are related to far-field and near-field records, respectively. A comparison between IDA curves suggests that the maximum inter-story drift is greatly reduced by the re-

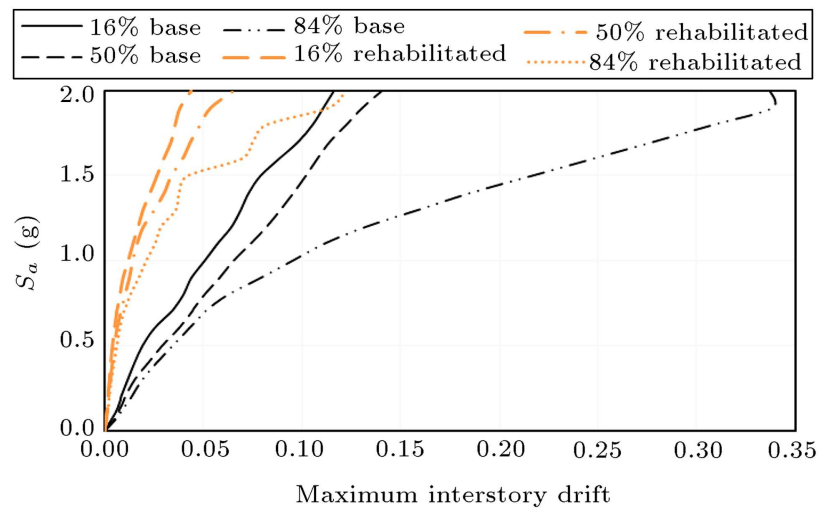

Figure 7. Incremental Dynamic Analysis (IDA) curves of the structure for three limit states under far-field records. 

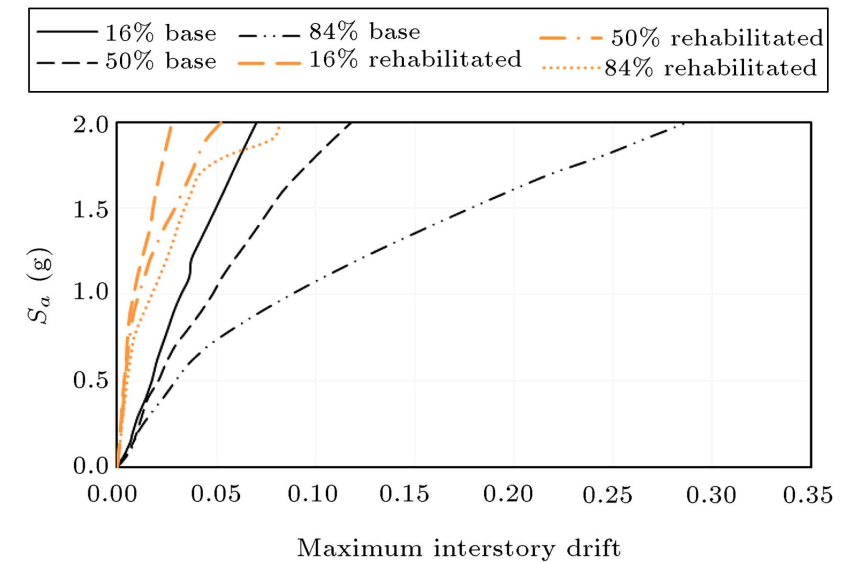

Figure 8. Incremental Dynamic Analysis (IDA) curves of the structure for three limit states under near-field records.

habilitation of the steel moment frame with steel shear wall due to the enhanced capacity of the structure.

\subsection{Sensitivity analysis}

In this section, Rayleigh's damping, yield strength, and strain hardening of the force-deformation relationship of the steel shear wall are assumed as probabilistic variables. Then, the sensitivity of the structural response rehabilitated with the steel shear wall is evaluated in relation to each of these parameters.

Base values and appropriate range of values for these probabilistic parameters were considered. Strain hardening is defined as a function of elastic stiffness in the force-deformation relationship for the steel shear wall. The sensitivity analysis for this parameter was performed with values of $0 \%, 2 \%$, and $5 \%$. The value of $2 \%$ was considered as the base value for this parameter. In Figure 9, IDA curves are presented for the structure rehabilitated with a steel shear wall with the base value and the range of variations. According to Figure 9(a), the structural response to the strain hardening parameter of the force-deformation relationship of the steel shear wall has minimum sensitivity. The sensitivity of the structural response to this parameter was obtained at about $13 \%$.

In this study, Rayleigh's damping of the structure was considered to be $2 \%$ as the base value in the sensitivity analysis, which was performed for this parameter with values of $0 \%, 2 \%$, and $5 \%$, as displayed in Figure 9(b). Regarding rehabilitation of the existing structure, the yield strength of the steel shear wall was 35 kip. This value was considered as the base value for yield strength. The evaluation results for the sensitivity of the structural response to yield strength of steel shear wall with values of 30,35 , and 40 kip are given in Figure 9(c). The sensitivity rates of the structural response to Rayleigh's damping and yield strength parameters were obtained about $16 \%$ and $23.6 \%$, respectively. As observed, the effect of yield strength parameter on the structural response was greater than those of other two parameters.

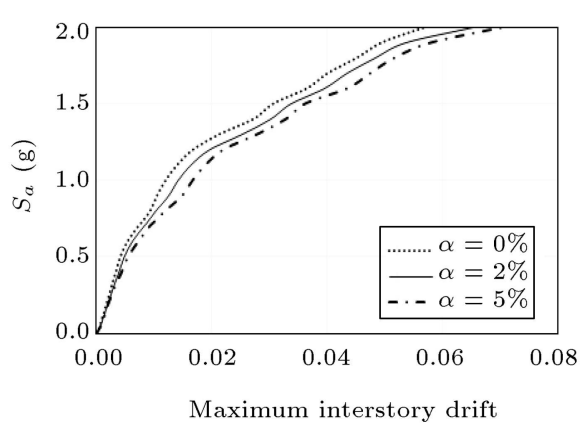

(a)

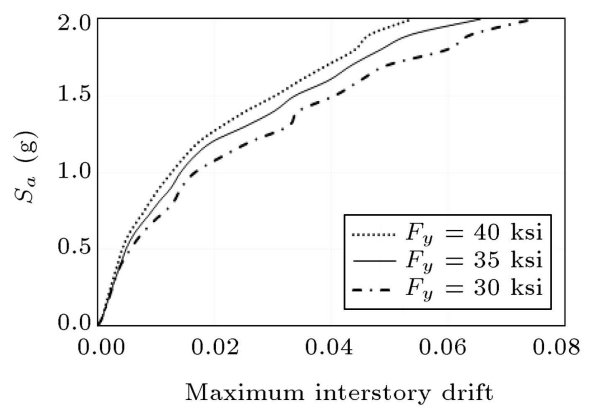

(c)

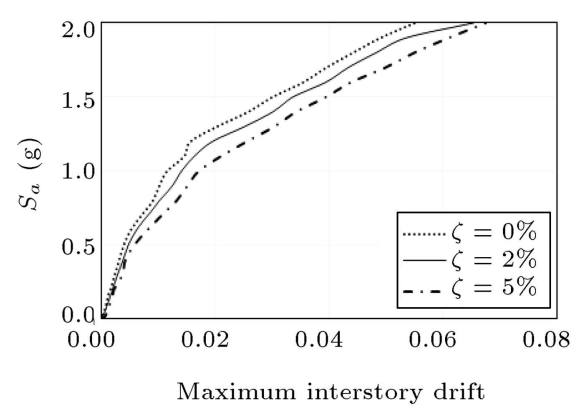

(b)

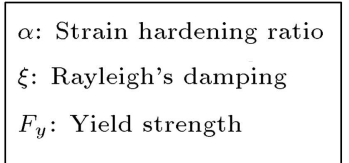

Figure 9. The sensitivity of median Incremental Dynamic Analysis (IDA) curve to probabilistic parameters: (a) The effect of the strain hardening of the force-deformation relationship of the steel shear wall, (b) the effect of Rayleigh's damping parameter of the structure, and (c) the effect of the yield strength parameter of the steel shear wall. 


\subsection{Quantification of the uncertainties}

The curves derived from IDA analysis and fragility curves of the structure under far-field and near-field records are shown in Figures 10-13. The seismic fragility analysis represents the exceedance probability of structural damage states against records with a specific intensity. The maximum inter-story drift ratio was selected as the damage indicator for fragility analysis, and three levels of drift $(0.7 \%, 2.5 \%$, and $5 \%)$ were determined based on the FEMA356 performance levels (IO, LS, and CP).

The uncertainties associated with seismic demand and structural capacity were taken into account. Tables 6 and 7 report the values of $\beta_{D \mid S_{a}}$ and $\beta_{R}$ for pre- and post-rehabilitation with consideration of the uncertainties. The median value of fragility $\left(\bar{S}_{a}\right)$ in terms of spatial acceleration was calculated through Eq. (7) for the structural pre- and post-rehabilitation. Furthermore, this parameter was calculated for the
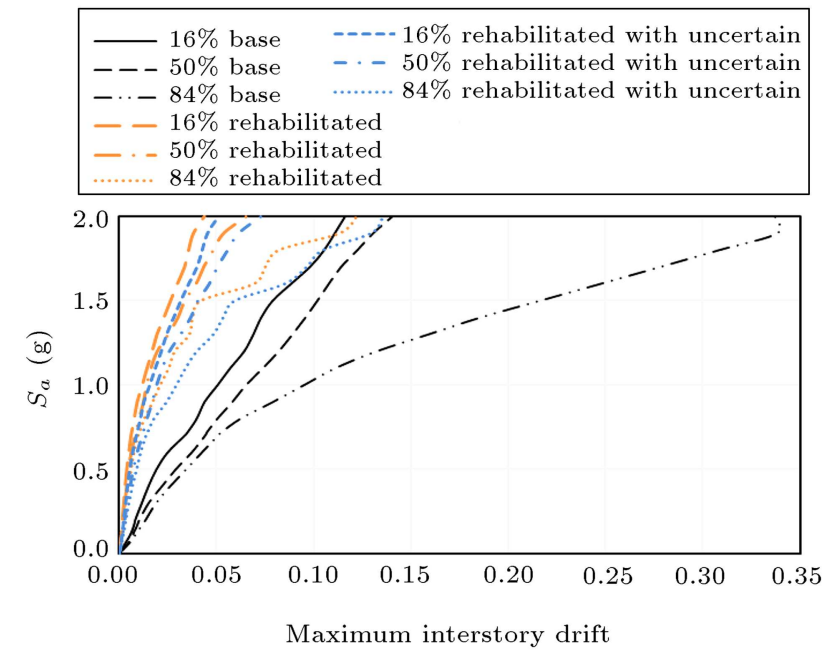

Figure 10. Incremental Dynamic Analysis (IDA) curve of the structure under far-field records.

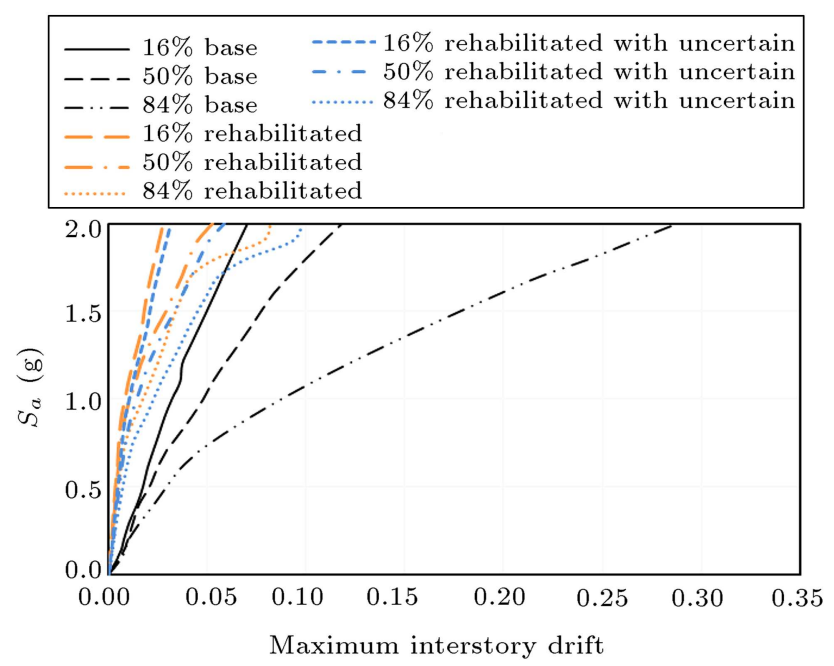

Figure 11. Incremental Dynamic Analysis (IDA) curve of the structure under near-field records.

rehabilitated structure in terms of uncertainties. The fragility curves of the rehabilitated structure with and without consideration of uncertainties are demonstrated at performance levels for far-field and near-field records in Figures 12 and 13, respectively.

According to Tables 6 and 7 , with the rehabilitation of the structure, the median value of fragility in the LS limit state increased from $0.47 \mathrm{~g}$ to $1.27 \mathrm{~g}$ under farfield records and from $0.57 \mathrm{~g}$ to $1.49 \mathrm{~g}$ under near-field records. As can be seen, following the rehabilitation of the structure, the median values of fragility also grow in other limit states. The comparison of fragility curves of the rehabilitated structure with and without consideration of uncertainties indicated that consideration of uncertainties had reduced the median value of fragility. Comparison of IDA curves of the rehabilitated structure with and without consideration of uncertainties demonstrated that uncertainties increased the maximum inter-story drift up to $27.6 \%$ and $16.4 \%$

Table 6. Seismic demand and median fragility values of structures under far-field records.

\begin{tabular}{|c|c|c|c|c|c|c|c|}
\hline \multirow{2}{*}{ Case } & \multirow{2}{*}{$\boldsymbol{\beta}_{D \mid S_{a}}$} & \multicolumn{3}{|c|}{$\boldsymbol{\beta}_{R}$} & \multicolumn{3}{|c|}{$\bar{S}_{a}(g)$} \\
\hline & & IO & $\mathbf{L S}$ & CP & IO & $\mathbf{L S}$ & $\mathbf{C P}$ \\
\hline Base building & 0.32 & 0.41 & 0.41 & 0.36 & 0.11 & 0.47 & 0.79 \\
\hline Rehabilitated building & 0.25 & 0.35 & 0.35 & 0.29 & 0.63 & 1.27 & 1.82 \\
\hline Rehabilitated building with consideration of uncertainties & 0.24 & 0.34 & 0.34 & 0.28 & 0.59 & 1.22 & 1.73 \\
\hline
\end{tabular}

Table 7. Seismic demand and median fragility values of structures under near-field records.

\begin{tabular}{|c|c|c|c|c|c|c|c|}
\hline \multirow{2}{*}{ Case } & \multirow{2}{*}{$\boldsymbol{\beta}_{D \mid S_{a}}$} & \multicolumn{3}{|c|}{$\boldsymbol{\beta}_{R}$} & \multicolumn{3}{|c|}{$\bar{S}_{a}(g)$} \\
\hline & & IO & $\mathbf{L S}$ & $\mathbf{C P}$ & IO & LS & $\mathbf{C P}$ \\
\hline Base building & 0.38 & 0.45 & 0.45 & 0.41 & 0.13 & 0.57 & 1 \\
\hline Rehabilitated building & 0.26 & 0.36 & 0.36 & 0.30 & 0.74 & 1.49 & 2.14 \\
\hline Rehabilitated building with consideration of uncertainties & 0.25 & 0.35 & 0.35 & 0.29 & 0.71 & 1.43 & 2.03 \\
\hline
\end{tabular}




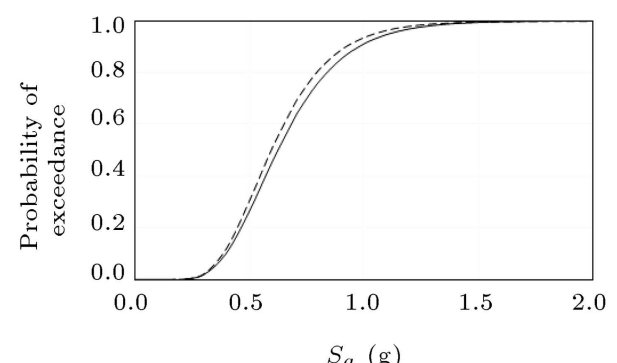

(a)

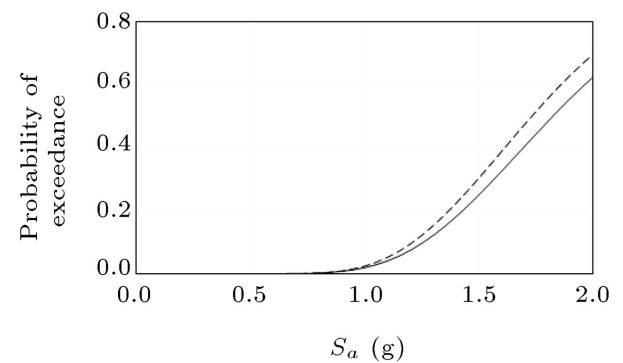

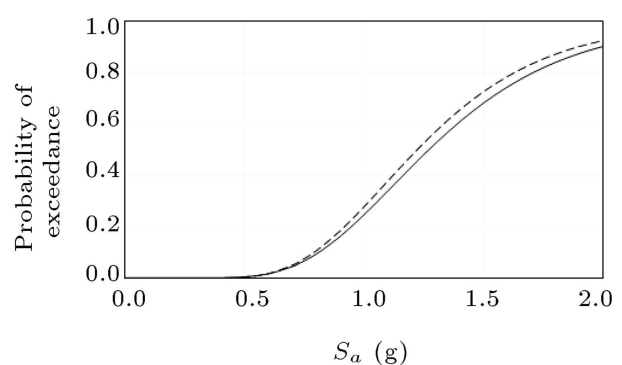

(b)

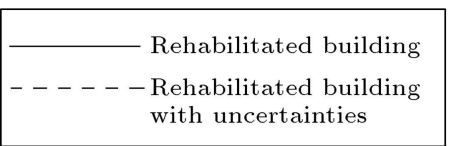

(c)

Figure 12. Fragility curve for different limit states under far-field records: (a) Immediate Occupancy (IO) limit state, (b) Life Safety (LS) limit state, and (c) Collapse Prevention (CP) limit state.

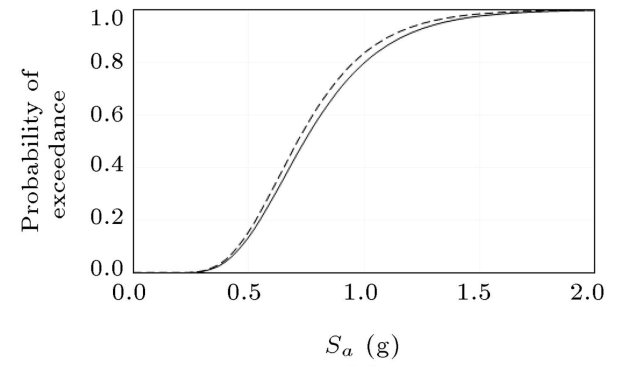

(a)

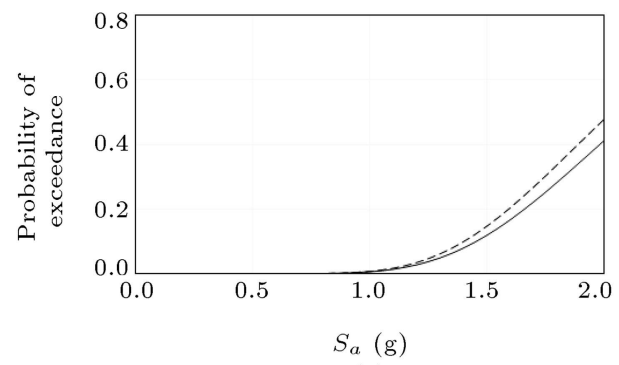

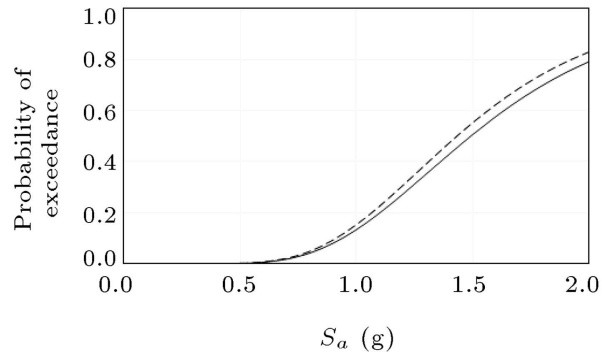

(b)

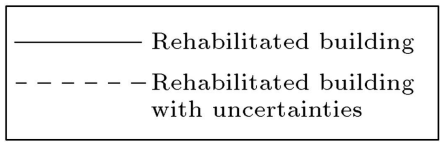

(c)

Figure 13. Fragility curve for different limit states under near-field records: (a) Immediate Occupancy (IO) limit state, (b) Life Safety (LS) limit state, and (c) Collapse Prevention (CP) limit state.

under far-field and near-field records, respectively. It is suggested that consideration of uncertainties reduces the existing conservatism.

\subsection{Annual exceedance probability of the limit states}

The annual exceedance probability of three limit states was calculated through Eq. (9) for the base and rehabilitated buildings with and without consideration of uncertainties. In Eq. (9), $k_{0}$ and $k$ are seismic hazard parameters equal to $3.03 \mathrm{e}-4$ and 2.69 for Los Angeles city [37]. The results of annual exceedance probability are presented in Tables 8 and 9 . The annual exceedance probability of the IO limit state decreased from 0.2109 to 0.0016 and from 0.1524 to 0.0011 with the rehabilitation of the structure under far-field and near-field records, respectively. This probability also diminished for LS and CP limit states, suggesting that the seismic performance of the structure was better through the rehabilitation of the structure. 
Table 8. Annual exceedance probability of three limit states under far-field records.

\begin{tabular}{lccc}
\hline \multirow{2}{*}{ Case } & \multicolumn{3}{c}{$\begin{array}{c}\text { Annual exceedance } \\
\text { probability }\end{array}$} \\
\cline { 2 - 4 } & ( $\left.\boldsymbol{P}_{\boldsymbol{L S}}\right)$ \\
\hline Base building & 0.2109 & 0.00424 & 0.000913 \\
$\begin{array}{l}\text { Rehabilitated building } \\
\text { Rehabilitated building } \\
\text { with consideration of }\end{array}$ & 0.0016 & 0.00025 & 0.000082 \\
\begin{tabular}{l} 
uncertainties \\
\hline
\end{tabular} & 0.0019 & 0.00027 & 0.000092 \\
\hline
\end{tabular}

Table 9. Annual exceedance probability of three limit states under near-field records.

\begin{tabular}{lccc}
\hline \multirow{2}{*}{ Case } & \multicolumn{3}{c}{$\begin{array}{c}\text { Annual exceedance } \\
\text { probability }\end{array}$} \\
\cline { 2 - 4 } & IO & LS & CP \\
\hline Base building & 0.1524 & 0.00286 & 0.000557 \\
Rehabilitated building & 0.0011 & 0.00017 & 0.000048 \\
$\begin{array}{l}\text { Rehabilitated building } \\
\text { with consideration of }\end{array}$ & 0.0012 & 0.00018 & 0.000061 \\
uncertainties & & & \\
\hline
\end{tabular}

The results revealed that the annual exceedance probability of the IO limit state increased from 0.0016 to 0.0019 and from 0.0011 to 0.0012 with consideration of uncertainties in the rehabilitated structure under far-field and near-field records, respectively. Finally, a comparison between the results of Tables 8 and 9 showed that a reduction or an increase in annual exceedance probability under far-field records was greater than that under near-field records. Based on the response spectrum of selected far-field records, this may be due to the greater impact of these records in the main period of the rehabilitated structure.

\section{Conclusions}

In this study, a 3-story structure of the SAC project was selected and verified in OpenSees software. The studied structure was then analyzed and rehabilitated with a steel shear wall. Near-field and far-field records were used for incremental dynamic analysis and these records were scaled based on the design spectrum for the site. The selected records involved extensive variations of the ground motion characteristics. For the selected seismic records, the structure was subjected to incremental dynamic analysis with basic parameters. The results of this step captured the uncertainty caused by various seismic records. As demonstrated by analysis results, the far-field records had greater effects on the results due to their greater impact on the main period of the rehabilitated structure.
At the next step, by assuming Rayleigh's damping, yield strength, and strain hardening of the forcedeformation relationship of steel shear wall as probabilistic variables, an effective number of structural models were generated and subjected to an incremental dynamic analysis of selected records. The results of this step included both aleatory and epistemic uncertainties.

The sensitivity of structural response to each of the selected probability parameters was investigated under sensitivity analysis. The results of sensitivity analysis revealed that the response of the structure had the least sensitivity to the strain hardening parameter of the force-deformation relationship of the steel shear wall $(13 \%)$ and the highest sensitivity to the yield strength parameter of the steel shear wall (23.6\%).

In this study, the incremental dynamic analysis was carried out on the pre- and post-rehabilitation structures. The obtained Incremental Dynamic Analysis (IDA) curves revealed that rehabilitation of the steel moment frame with a steel shear wall significantly reduced the maximum inter-story drift of the structure in the considered limit states. Comparison of the rehabilitated structure curves with and without consideration of uncertainties demonstrated that taking uncertainties in account increased the maximum interstory drift up to $27.6 \%$ and $16.4 \%$ under far-field and near-field records, respectively. It can be suggested that consideration of uncertainties reduces the existing conservatism.

Finally, the annual exceedance probability of the selected limit states was calculated for the base and rehabilitated buildings with and without consideration of uncertainties. The annual exceedance probability of the selected limit states diminished through the rehabilitation of the structure under far-field and nearfield records, suggesting that the seismic performance of the structure improved through the rehabilitation of the structure. The results revealed that the annual exceedance probability of the three limit states increased by $8-18.75 \%$ and $5.9-27.1 \%$ with consideration of uncertainties in the rehabilitated structure under farfield and near-field records, respectively.

\section{References}

1. Siahos, G. and Dritsos, S. "Procedural assumption comparison for old buildings via pushover analysis including the ASCE 41 update", Earthquake Spectra, 26(1), pp. 187-208 (2010). https://doi.org/10.1193/1.3272266

2. Acun, B. and Sucuoglu, H. "Performance of reinforced concrete columns designed for flexure under severe displacement cycles", ACI Structural Journal, 107(3), pp. 364-371 (2010).

3. Acun, B. and Sucuoglu, H. "Evaluation of the per- 
formance limit states of reinforced concrete columns in view of experimental observations", Teknik Dergi, 22(3), pp. 5523-5541 (2011).

4. Ricci, P., Verderame, G.M., and Manfredi, G. "ASCE/SEI 41 provisions on deformation capacity of older-type reinforced concrete columns with plain bars", Structural Engineering, 139(12), p. 04013014 (2013). http://doi.org/10.1061/(ASCE)ST.1943-541 X.0000701

5. Hacking, I., The Emergence of Probability: A Philosophical Study of Early Ideas about Probability, Induction and Statistical Inference, Cambridge University Press (2006).

6. Zareian, F. and Krawinkler, H. "Assessment of probability of collapse and design for collapse safety", Earthquake Engineering \& Structural Dynamics, 36(13), pp. 1901-1914 (2007). https://doi.org/10.1002/eqe.702

7. Dolsek, M. "Incremental dynamic analysis with consideration of modeling uncertainties", Earthquake Engineering \& Structural Dynamics, 38(6), pp. 805-825 (2009). https://doi.org/10.1002/eqe.869

8. Vamvatsikos, D. and Fragiadakis, M. "Incremental dynamic analysis for estimating seismic performance sensitivity and uncertainty", Earthquake Engineering \& Structural Dynamics, 39(2), pp. 141-163 (2010). https://doi.org/10.1002/eqe.935

9. Vamvatsikos, D. "Seismic performance uncertainty estimation via IDA with progressive accelerogramwise latin hypercube sampling", Structural Engineering, 140(8), p. A4014015 (2014). https://doi.org/ 10.1061/(ASCE)ST.1943-541X.0001030

10. Kaveh, A., Massoudi, M.S., and Bagha, M.G. "Structural reliability analysis using charged system search algorithm", Iranian Journal of Science and Technology, Transactions of Civil Engineering, 38, pp. 439448 (2014).

11. Mathiasson, A. and Medina, R. "Seismic collapse assessment of a 20-story steel moment-resisting frame structure", Buildings, 4(4), pp. 806-822 (2014). https://doi.org/10.3390/buildings4040806

12. Torabian, S. and Taghikhany, T. "Assessment of seismic collapse uncertainties of steel moment resisting frames by means of single degree of freedom systems", Proceedings of the Institution of Mechanical Engineers, Part O: Journal of Risk and Reliability, 228(5), pp. 504-517 (2014). https://doi.org/10.1177/1748006x14535760

13. Kazantzi, A.K., Vamvatsikos, D., and Lignos, D.G. "Seismic performance of a steel moment-resisting frame subject to strength and ductility uncertainty", Engineering Structures, 78, pp. 69-77 (2014). https://doi.org/10.1016/j.engstruct.2014.06.044

14. Lignos, D.G. and Krawinkler, H. "Deterioration modeling of steel components in support of collapse prediction of steel moment frames under earthquake loading", Structural Engineering, 137(11), pp. 1291-1302 (2011). https://doi.org/ 10.1061/(ASCE)ST.1943-541X.0000376

15. Tubaldi, E., Ragni, L., and Dall'Asta, A. "Probabilistic seismic response assessment of linear systems equipped with nonlinear viscous dampers", Earthquake Engineering \& Structural Dynamics, 44(1), pp. 101120 (2015). https://doi.org/10.1002/eqe.2461

16. Asgarian, B. and Ordoubadi, B. "Effects of structural uncertainties on seismic performance of steel moment resisting frames", Constructional Steel Research, 120, pp. $132-142(2016)$. https://doi.org/10.1016/j.jcsr.2015.12.031

17. Hajirasouliha, I., Pilakoutas, K., and Mohammadi, R.K. "Effects of uncertainties on seismic behavior of optimum designed braced steel frames", Steel and Composite Structures, 20(2), pp. 317-335 (2016). http://dx.doi.org/10.12989/scs.2016.20.2.317

18. Zhang, H., Shayan, S., Rasmussen, K.J., and Ellingwood, B.R. "System-based design of planar steel frames, I: Reliability framework", Constructional Steel Research, 123, pp. 135-143 (2016). http://doi.org/10.1016/j.jcsr.2016.05.004

19. Holicky, M., Retief, J.V., and Sykora, M. "Assessment of model uncertainties for structural resistance", Probabilistic Engineering Mechanics, 45, pp. 188-197 (2016).

https://doi.org/10.1016/ j.probengmech.2015.09.008

20. Dyanati, M., Huang, Q., and Roke, D. "Cost-benefit evaluation of self-centering concentrically braced frames considering uncertainties", Structure and Infrastructure Engineering, 13(5), pp. 537-553 (2017). https://doi.org/10.1080/15732479.2016.1173070

21. Jiang, L. and Ye, J. "Seismic risk assessment of a 2-storey steel-sheathed CFS building considering different sources of uncertainty", Structures, 16, pp. $347-357$ (2018). https://doi.org/10.1016/ j.istruc. 2018.10 .010

22. Norouzi, A.H. and Gerami, M. "Quantifying response variability of steel moment frames due to seismic uncertainties", Asian Journal of Civil Engineering, 20(4), pp. 503-514 (2019). https://doi.org/10.1007/s42107019-00115-3

23. Piluso, V., Pisapia, A., Castaldo, P., and Nastri, E. "Probabilistic theory of plastic mechanism control for steel moment resisting frames", Structural Safety, 76, pp. 95-107 (2019). https:// doi.org/10.1016/j.strusafe.2018.08.003

24. FEMA "Quantification of building seismic performance factors", Report No. FEMA P695, Redwood city, CA, Applied Technology Council (2009).

25. Gupta, A. and Krawinkler, H. "Seismic demands for 
the performance evaluation of steel moment resisting frame structures", Doctoral Dissertation, Stanford University (1998).

26. McKenna, F., Fenves, G.L., and Scott, M.H., Open System for Earthquake Engineering Simulation, University of California, Berkeley, CA (2000). www.opensees.berkeley.edu

27. SEAOC Seismology Committee "Recommended lateral force requirements and commentary", Structural Engineers Association of California, Sacramento, CA (1999).

28. Whittaker, A., Atkinson, G., Baker, J., et al. "Selecting and scaling earthquake ground motions for performing response-history analyses", No. Grant/Contract Reports (NISTGCR)-11-917-15 (2011).

29. Council, B.S.S. "Prestandard and commentary for the seismic rehabilitation of buildings", Report FEMA356, Washington, DC (2000).

30. Ellingwood, B.R. and Kinali, K. "Quantifying and communicating uncertainty in seismic risk assessment", Structural Safety, 31(2), pp. 179-187 (2009). https://doi.org/10.1016/j.strusafe.2008.06.001

31. Kinali, K. and Ellingwood, B.R. "Seismic fragility assessment of steel frames for consequence-based engineering: A case study for Memphis, TN", Engineering Structures, 29(6), pp. 1115-1127 (2007). https:// doi.org/10.1016/j.engstruct.2006.08.017

32. Sadowski, A.J. and Rotter, J.M. "Solid or shell finite elements to model thick cylindrical tubes and shells under global bending", Mechanical Sciences, 74, pp. 143-153 (2013). https://doi.org/ 10.1016/j.ijmecsci.2013.05.008

33. Sadowski, A.J., Rotter, J.M., Reinke, T., and Ummenhofer, T. "Statistical analysis of the material properties of selected structural carbon steels", Structural Safety, 53, pp. 26-35 (2015). https:// doi.org/10.1016/j.strusafe.2014.12.002
34. Porter, K.A., Beck, J.L., and Shaikhutdinov, R.V. "Investigation of sensitivity of building loss estimates to major uncertain variables for the Van Nuys testbed", PEER Report 2002/03 (2002).

35. Melchers, R.E., Structural Reliability Analysis and Prediction, John Wiley \& Sons, New York (1999).

36. JCSS, J. "Probabilistic model code", Joint Committee on Structural Safety (2001).

37. Hossain, M.R., Ashraf, M., and Padgett, J.E. "Risk-based seismic performance assessment of yielding shear panel device", Engineering Structures, 56, pp. 1570-1579 (2013). https://doi.org/10.1016/ j.engstruct.2013.07.032

\section{Biographies}

Mahdiye Maddahi was born in Tabriz, Iran. She obtained her BS and MS degrees in Civil and Earthquake Engineering in 2010 and 2012, respectively. Her research interests include shear wall, reliability, and rehabilitation of structures. She is presently a $\mathrm{PhD}$ student at Semnan University.

Mohsen Gerami received his PhD degree in Earthquake Engineering in 2003. He then joined Semnan University where he is presently an Associate Professor of Earthquake Engineering. His major research interests include higher mode effects on seismic behavior of structures, cyclic behavior of connections of structures, seismic rehabilitation, vulnerability of structures, and structural reliability.

Hossein Naderpour received his $\mathrm{PhD}$ degree in Structural Engineering in 2010. He then joined Semnan University where he is presently an Associate Professor of Structural Engineering. His major research interests include the application of soft computing in structural engineering, structural reliability, structural optimization, and damage detection of structures. 